\title{
The Role of Family Resilience on Parental Well-Being and Resilience Levels
}

\author{
Ioanna Aivalioti1,2, Christos Pezirkianidis ${ }^{3}$ \\ ${ }^{1}$ Institution of Counselling and Psychological Studies, I.C.P.S., Athens, Greece \\ ${ }^{2}$ University of Central Lancashire, Preston, UK \\ ${ }^{3}$ Panteion University of Social and Political Sciences, Athens, Greece \\ Email: christospez@hotmail.com
}

How to cite this paper: Aivalioti, I., \& Pezirkianidis, C. (2020). The Role of Family Resilience on Parental Well-Being and Resilience Levels. Psychology, 11, 1705-1728. https://doi.org/10.4236/psych.2020.1111108

Received: September 25, 2020

Accepted: November 16, 2020

Published: November 19, 2020

Copyright (C) 2020 by author(s) and Scientific Research Publishing Inc. This work is licensed under the Creative Commons Attribution International License (CC BY 4.0).

http://creativecommons.org/licenses/by/4.0/

\begin{abstract}
Family well-being, conceptualized as the interaction between family members' mental, physical health and psychological resilience, and family resilience, is crucial for the optimal functioning of the family unit. However, most research investigating the relationship between family resilience and psychological outcomes has focused on children instead of parents and no relevant research in the general Greek population has been conducted so far. Therefore, a sample of 83 Greek parents was recruited and the relationship of family resilience with parental well-being and parental resilience was examined. In addition, differences in the aforesaid constructs between mothers and fathers were explored. Results indicated that parents, who reported higher levels of coping strategies in terms of family resilience, were more likely to report higher levels of well-being and psychological resilience. Nevertheless, no significant differences in family resilience, parental well-being, and parental resilience between mothers and fathers were identified. Methodological limitations and future recommendations were discussed.
\end{abstract}

\section{Keywords}

Family Resilience, Parental Resilience, Well-Being, Psychological Resilience, Parents

\section{Introduction}

Resilience can be broadly defined as the ability to persevere in the face of adversity (Southwick, Bonanno, Masten, Panter-Brick, \& Yehuda, 2014). Adversity describes any circumstance that may threaten the development and well-being of an individual (Masten, 2001). In the family context, family resilience refers to the capacity of the entire family unit to be resilient (Walsh, 2012). According to 
Walsh (2003), persevering adversity or serious crises hinder the functioning of the family unit, and impact all family members and the relationship between them. Key family processes pertaining to resilience mechanisms have the potential to mediate recovery from significant stressors by buffering stress, mitigating dysfunction and facilitating optimal adaptation.

Intertwined with the concept of family resilience, family well-being (FWB) can be defined as the interaction between a number of factors (i.e. parental mental and physical health, family resilience and self-sufficiency) that are critical for the optimal functioning of the family unit (Newland, 2015) and necessary for the well-being of family members (e.g. Merz, Consedine, Schulze, \& Schuengel, 2009; Umberson, Crosnoe, \& Reczek, 2010). Over the life course and across different types of family relationships, links between individuals-and their inherent interdependence-contribute to individual well-being by enhancing their sense of meaning, and through social and physical resources (Thomas, Liu, \& Umberson, 2017). In the context of parent-child relationships, past research has indicated links between FWB and favourable psychological outcomes (e.g. increased sense of meaning; Nelson, Kushlev, English, Dunn, \& Lyubomirsky, 2012) as well as stressors (e.g. parental stress; Martinviita-Hietala, Joskitt, Ebeling, Yliherva, \& Moilanen, 2018; Thomas et al., 2017).

Besides the significance for parents, FWB is also associated with the well-being of adolescent and adult children (Brown, Manning, \& Stykes, 2015). For example, open and positive family (parental) communication has been associated with adolescent psychological adjustment in school and good mental health (López, Musitu, \& Herrero, 2005). The role of FWB is central in youth resilience and this has long been investigated in family resilience and parenting research (Fernandez, Schwartz, Chun, \& Dickson, 2012). As an example, Anagnostaki and colleagues (2016) cross-sectionally study investigated resilience, personal and family resources of immigrant youth (Albanian) in Greek schools. The results showed that independent of personal resources, family social adversity and family resources were significant predictors of academic achievement in both immigrant and Greek-born students. The results of these studies were congruent with a collectivist culture perspective (i.e. found in both Mexican, Greek and Albanian cultures), where family well-being precedes individual well-being. Following this line of thought, in this cultural context, psychosocial factors ("we" or "us") may be considered antecedents of psychological factors ("self") highlighting the importance of FWB (Anagnostaki, Pavlopoulos, Obradović, Masten, \& Motti-Stefanidi, 2016).

The purpose of the current research is to understand the associations between family resilience, parental well-being, and parental resilience in a sample of Greek families. Walsh's $(1996,2003,2012)$ family resilience framework was selected as a theoretical guide for this research. The framework is discussed in this chapter, and evidence is presented on the relations between individual/family resilience and a range of psychological outcomes. 


\section{Conceptualization of Family Resilience}

Walsh's $(1996,2003,2012)$ conceptualisation of family resilience focuses on the functional family unit, considering risk and resilience through a dynamic process, rather than viewing family members as resources for individual resilience (Masten \& Cicchetti, 2016). The concept draws from theories and research evidence on family stress combining an ecological and a developmental perspective to view the family vis-à-vis the sociocultural context (Mackay, 2003; Simon, Murphy, \& Smith, 2005). From the ecological perspective, risk and resilience are considered to be a product of the interaction between the individual and family risk or resilience, and coping with stressful experiences over the life course (Walsh, 2012). Sociocultural context and the family process may negate or support genetic influences or biological predispositions (Moore \& Neiderhiser, 2014). Failure to cope with significant life stressors or accrued stress may result in distress (Walsh, 2012). Through the dynamic process described in the resilience framework, cultural, social and spiritual resources are considered to foster and strengthen resilience.

From a developmental perspective, individual and family resilience is considered in relation to the impact of adversity across the lifetime-the family unit adapts to the impact of major life stressors over time (Walsh, 2016a). The impact of challenging and disruptive life situations is considered on three levels. First, challenges emerge (i.e. adverse situations) and continue to impact family members across time. Individual and family responses change and adapt over the life course. For example, the family members adapt to change in family processes following a divorce as the parents relocate, changes in living arrangements occur, and parent-child relationships are readjusted. Second, varied strategies to counter cumulative stressors are necessary. Insufficient strategies to counter accumulated strain and changing needs over time such as those resulting from chronic illness in the family may lead to dysfunction (Roland, 2016). Third, multigenerational family structures change over time and across generations alongside changes in culture (e.g. becoming more diverse; Walsh, 2016b) and unprecedented challenges (e.g. economic, political or social disruptions). They way in which family members can manage a critical event, adequately reorder, and reinvest in life will determine their short- and long-term adaptation to their life and their relationships (Walsh, 2016a).

In practice, the value of the family resilience framework lies in its empirical support by a large body of research evidence on optimal family functioning processes and resilience (as described in Walsh, 2016c). Findings indicate that family resilience is organised in three areas (Walsh, 2012). First, family belief systems (FBS) facilitate meaning of adverse events (i.e. contextualise stress, attribute cause, manage and set expectations). For example, a qualitative study on family resilience in Australian adults where a parent had been diagnosed with a mental illness reported that FBS were an important domain (Powel et al., 2015). Specifically, the family context (e.g. open communication, acknowledging 
and making sense of mental illness), regular family routines (e.g. to manage unpredictability of diagnosed parent) and family connectedness (e.g. shared humour as a safe way to express emotions) were key to developing family resilience.

Second, organisational patterns including the structure of the family, the level of connectedness and access to socioeconomic resources may enhance family resilience. This was directly supported by a recent study employing a 3-round Delhi design aimed at developing a resilience program to strengthen family functioning in a South African rural community (Isaacs, Roman, \& Savahl, 2018). The study findings suggested that mapping out existing social (e.g. social grants available) and economic resources (e.g. learning about financial management), in addition to family connectedness (e.g. understanding roles and rules, developing sensitivity for each other) could minimise the impact of adversity (Black \& Lobo, 2008). Third, communication processes facilitate emotional sharing among family members (emotional expression), enhance clarity in the case of adverse events (clear information), and promote resourcefulness and maintain a proactive stance (collaboration and preparedness) in an adverse event. Across a number of studies in the family resilience literature, communication of emotion and information has been found to be associated with highly functioning families (e.g. Coyle et al., 2009; MacPhee, Lunkenheimer, \& Riggs, 2015; Matjasko, Vivolo-Kantor, Henry, Gorman-Smith, \& Schoeny, 2013). The three areas described are considered to work interactively and synergistically in the family resilience process. FBS facilitate connectedness, and in turn, enhance collaboration and optimal family functioning.

\section{Parental and Family Well-Being}

Subjective well-being can be described as flourishing on a cognitive and an affective level encompassing psychological, emotional and psychosocial flourishing (Keyes, 2002). Consistent with a positive psychology perspective, well-being is not limited to the absence of negative function (Butler \& Kern, 2016). Well-being has also been thought of as ranging on a spectrum-from hedonic ("feel good") to eudaimonic approaches (the "good life"; Ryan \& Deci, 2001).

According to Seligman (2011), well-being emerges from five pillars: positive emotion $(P)$, engagement $(E)$, positive relationships $(R)$, sense of meaning $(M)$, and accomplishments (A; PERMA model). Positive emotion can be defined as a cognitive and emotional mental state shown to be associated with increased resilience and life satisfaction because the experiencing of positive emotions: 1) broadens the available thoughts and actions, 2) creates more and deeper positive emotions, 3) builds enduring resources that protect individuals against adversity acting as an ammition storage, and 4) cancels the unpleasant effects of experiencing negative emotions (Cohn, Fredrickson, Brown, Mikels, \& Conway, 2009; Fredrickson, 2001; Fredrickson, Tugade, Waugh, \& Larkin, 2003; Garland, Fredrickson, Kring, Johnson, Meyer, \& Penn, 2010; Gendron, 2010; Tugade \& Fredrickson, 2004). Engagement may be expressed as a behavioural, cognitive 
and emotional construct characterised by feelings of vigour, absorption and dedication (Schaufeli, Bakker, \& Salanova, 2006). Social relationships are central to living, and a substantial body of evidence supports that high-quality relationships are associated with increased mental and physical health (Howick, Kelly, \& Kelly, 2019). A sense of meaning involves a direction in life, self-worthiness and purpose to one's actions (Steger, 2012). Meaning has been shown to be associated with favourable outcomes, such as high levels of positive social interaction, life satisfaction, and good physical health (Bonebright, Clay, \& Ankenmann, 2000; Reker \& Chamberlain, 2000; Ryff, Singer, \& Love, 2004; Steger \& Shin, 2010; Van Tongeren, Hill, Krause, Ironson, \& Pargament, 2017). Accomplishment describes the subjective experience of working and attaining goals, task mastery, self-efficacy, and is theorised to be a core human need (Ryan \& Deci, 2000).

In the family context, life-long intergenerational relationships (relationships between parents, children and siblings) have been shown to be associated to family members' physical and mental well-being (e.g. Polenick, DePasquale, Eggebeen, Zarit, \& Fingerman, 2016). To date, the majority of research on resilience available has focused on children's well-being and to a lesser extent, parental well-being. While parental well-being has been shown to be associated with parental resilience, there is a lack of studies concerning the effects of an adversity on parental wellbeing and resilience albeit their significance has been highlighted and to add more there is a lack of studies on the relationship between family resilience processes and parental mental health or resilience (Gerstein, Crnic, Blacher, \& Baker, 2009; Lester et al., 2016).

\section{Parental and Family Resilience}

Psychological resilience refers to a dynamic process of one's ability to adapt to significant adversity. Contexts (such as culture or family) form part of the individual's experience (varying in proximity) and transact with one another over time to impact development and adaptability (Luthar, Cicchetti, \& Becker, 2000). It has been suggested that individual, familial and societal domains are interrelated and determine individual resilience (Mandleco \& Peery, 2000; Tian, Liu, \& Shan, 2018). Focusing on the familial domain, significant life stressors are known to impact family and individual psychological resilience. Parental resilience may be defined as parental capacity for competence (personal resources including skills and knowledge) and quality parenting (positive response to children's changing needs) in spite of personal, family, and social circumstances (Crawford, 2011). A number of factors may determine, buffer and maintain parental resilience including self-efficacy, psychological functioning, and family connectedness (Gavidia-Payne, Denny, Davis, Francis, \& Jackson, 2015).

Long-term exposure to stress such as frequent absence of a parent (e.g. due to work commitments) or mental health problems (e.g. disruption to parenting) may be considered a significant life stressor from the child's perspective (Smith, 2003). Long-term exposure to stress impacts FWB and is often observed in fami- 
lies with (absent) military parents on active duty (Osofsky \& Chartrand, 2013). During developmental stages, children with military parents serving during wartime (e.g. deployment) are at increased risk for social, behavioural and emotional problems as well as enhanced stress for the family unit (Lester \& Flake, 2013). Similarly, children of contract migrant mothers (e.g. from Indonesia, or Vietnam) report decreased happiness and well-being (due to the experience of separation) when compared to non-migrant families (however, these children exhibit greater resilience attributed to maternal absence; Jordan \& Graham, 2012; Ungar, 2004). The significance of parental presence (and functioning) for children and the family (FWB) is demonstrated by research showing parental resilience to a profound effect on child development during adverse circumstances (Ungar, 2004).

Research on resilience does not concern only the families and parents that face extreme life stressors but also every parent or family that face everyday stressors. However, research on parental resilience is scarce and the few studies available were conducted in specific populations. For instance, parents of children diagnosed with physical illnesses (e.g. cancer) or developmental problems (e.g. autism) are exposed to stressors for prolonged periods of time associated with their child's health (e.g. Clarke, McCarthy, Downie, Ashley, \& Andreson, 2009; Ilias, Cornish, Kummar, Park, \& Golden, 2018). For example, the impact of a cancer diagnosis is known to affect parental mental health (Gudmundsdottir, Schirren, \& Boman, 2011). In a cross-sectional study, Eilersen and colleagues (2015) investigated parental resilience factors and their association to mental health in a sample of families of children that had survived acute lymphoblastic leukaemia. The study results indicated that in comparison to a control group (a sample of parents of healthy children), parents of children who had survived cancer reported reduced resilience. In specific, parents' scored lower on four of five resilience factors including, perception of self (i.e. belief in self), planned future, family cohesion and social resources. Moreover, no differences were found with regards to general mental health between the two groups. It is possible that the experience of acute lymphoblastic leukaemia reduced psychological resources.

Another study examining parental resilience associated with child-related stress in the family was carried out by Bitsika, Sharpley and Bell (2013). The focus of the study was to investigate the effects of resilience on anxiety and depression in parents of children diagnosed with Autism Spectrum Disorder (ASD) in Australia. The results confirmed that parental levels of anxiety and depression were clinically meaningful and consistent with past research on Australian parents of children diagnosed with ASD (Bitsika \& Sharpley, 2004). Resilience levels were found to be lower in this sample in comparison to individuals diagnosed with an anxiety disorder. Parents reported feeling unable to cope with the demands related to their child and "being stretched beyond their personal limits" (Bitsika et al., 2013: p. 541). Bitsika and colleagues (2013) propose that resilience buffered, to a certain extent, the negative effects of anxiety and depression irres- 
pective of the level of stress experienced by parents. In other words, resilience-in part-determined parents' ability to meet daily parenting demands. This finding is consistent with Eilersen and colleagues' (2015) findings reporting decreased resilience levels in parents of children who had survived cancer.

Major life stressors that persist over time and impact the family unit (i.e. physical illness or developmental disorders of children) appear to make up the majority of the available research on parental resilience. While it has been shown that reported resilience of parents, who are living with such life stressors, is reduced, it is also suggested that this may be due to the interplay between resilience and anxiety and depression associated with child's condition (i.e. resilience may negate the negative effects of anxiety and depression, leading to a perceived-or actual-reduction of resilience resources; Bitsika et al., 2013; Eilersen, Hjemdal, Diseth, Le, \& Reinfjell, 2015). It is likely that the severity of such stressors may impact parental resilience (e.g. a bad prognosis of a child's health may further reduce parental resilience and hinder mental health outcomes). For example, Grant and colleagues' (2013) study showed that in comparison to parents of children diagnosed with an intellectual disability (ID), parents of children with Mycupolysaccharidosis type III (MPS III) reported lower resilience factors (e.g. less preference to plan ahead, to plan for the future).

A review of the available evidence demonstrates the need to research parental resilience in a sample of the general population (versus specific samples, such as parents of children with illness or disability). It is likely that parental resilience levels and processes (e.g. buffering effect) differ. Considering that increased and prolonged stress (such as that occurring from a life-threatening illness of a child) is associated with decreased parental resilience levels, it is likely that exposure to different types (e.g. adverse events in intervals) or levels of stress (low or moderate levels) may reveal different associations and potential mechanisms.

\section{Gender Differences}

Regarding intergenerational relationships, research indicates differences in experiences between men and women in terms of parenting and well-being outcomes (Thomas et al., 2017). Mothers are more likely to be involved and affected by intergenerational relationships by maintaining closer relationships with adult children (Swartz, 2009), experiencing greater parental pressure than fathers (Stone, 2007) and work more actively on family relationships contributing to greater distress (Erickson, 2005). Similarly, the majority of research available on parental resilience is limited and the available evidence has focused on maternal resilience with a few exceptions (e.g. Polenick et al., 2016). This is reflected in the gender differences explored (and reported) on parental resilience in some of the aforementioned studies.

In Eilersen and colleagues' (2015) study, resilience factors including perception of self, planned future, and family cohesion were found to be significant predictors of mental health for mothers of children that survived cancer. In Bit- 
sika and colleagues' (2013) study, mothers of children diagnosed with ASD were significantly more anxious and depressed compared to fathers. The results however indicated that mothers and fathers did not exhibit any differences on levels of parental resilience. Gender-specific analyses indicated that in spite sameness on resilience levels, it is likely that mothers reported higher anxiety and depression levels due to experiencing the burden of caring for their child more intensely. In Grant and colleagues' (2013) study, a gender analysis could not be conducted due to low participation of fathers in comparison to mothers (albeit low participation of fathers in paediatric palliative care is common; Macdonald, Chilibeck, Affleck, \& Cadell, 2010). While it is likely that women experience more poorer mental health (e.g. anxiety, depression) when compared to men due to gender roles or culture, it is also likely that this is not determined yet as men are underrepresented in the research literature. Further research exploring fathers' parenting resilience is necessary.

\section{Purpose of the Present Study}

The purpose of the present study is to explore the associations between family resilience, parental resilience and parental well-being in a sample of Greek parents. At present, and to the best of our knowledge, there are no available studies focusing on this topic in a sample of the general Greek population. The available studies have either focused on resilience and related outcomes of migrant children in Greece (e.g. Anagnostaki et al., 2016), or student resilience and psychological well-being in response to adverse events on a societal level (e.g. economic crisis; Hatzichristou, Lianos, \& Lampropoulou, 2017). In terms of contribution to the broader literature, the present study will focus on family resilience and enhance the understanding of the parenting perspective including the impact of family resilience on the well-being and resilience of parents.

Research hypotheses. In total, five hypotheses are proposed. Concerning the predictive role of family resilience on parental well-being and resilience, it is hypothesised that: (H1) Family resilience will be a statistically significant positive predictor of parental well-being. It is assumed that parents who display higher family resilience are more likely to report higher parental well-being (Gavidia-Payne et al., 2015; Polenick et al., 2016), and (H2) Family resilience will be a statistically significant positive predictor of parental resilience. It is expected that parents who display higher family resilience are more likely to report higher parental resilience (Tian et al., 2018).

Regarding differences in family resilience, parental well-being and parental resilience between mothers and fathers, it is postulated that: (H3) There will be a statistically significant difference in family resilience between fathers and mothers (Thomas et al., 2017), (H4) There will be a statistically significant difference in parental well-being between fathers and mothers (Bitsika et al., 2013), and (H5) There will be a statistically significant difference in parental resilience between fathers and mothers. Concerning H5, while one available study exploring 
gender differences on parental resilience did not report any significant differences (e.g. Bitsika et al., 2013), fathers are typically underrepresented in studies on parental resilience rendering this relation inconclusive (e.g. Grant et al., 2013). Therefore, exploring gender differences on parental resilience is expected to address this gap in the literature.

\section{Method}

\subsection{Participants}

A non-probability sample of 83 Greek parents was collected online through snowball sampling. An overrepresentation of women (76\%) was observed in the sample and a mean age of 42 years was reported $(M=41.86, S D=9.24)$. Approximately half of the participants had completed undergraduate studies (41\%), followed by those who had completed graduate studies (36\%). Finally, most parents were married (75\%) and reported having either one (52\%) or two children (39\%) (see Table 1).

\subsection{Measures}

A questionnaire battery comprised of three scales was prepared and distributed

Table 1. Demographic characteristics of the sample $(n=83)$.

\begin{tabular}{|c|c|c|}
\hline & $n$ & $\%$ \\
\hline \multicolumn{3}{|l|}{ Gender } \\
\hline Male & 20 & $24 \%$ \\
\hline Female & 63 & $76 \%$ \\
\hline \multicolumn{3}{|l|}{ Education } \\
\hline Primary education & 1 & $1 \%$ \\
\hline Secondary education & 14 & $17 \%$ \\
\hline Vocational education & 3 & $4 \%$ \\
\hline Undergraduate studies & 34 & $41 \%$ \\
\hline Postgraduate studies & 30 & $36 \%$ \\
\hline $\mathrm{PhD}$ & 1 & $1 \%$ \\
\hline \multicolumn{3}{|l|}{ Marital Status } \\
\hline Not married & 11 & $13 \%$ \\
\hline Married & 62 & $75 \%$ \\
\hline Divorced & 10 & $12 \%$ \\
\hline \multicolumn{3}{|l|}{ Number of Children } \\
\hline 0 & 1 & $1 \%$ \\
\hline 1 & 43 & $52 \%$ \\
\hline 2 & 32 & $39 \%$ \\
\hline 3 & 7 & $8 \%$ \\
\hline
\end{tabular}


online via Google Forms. Five demographic questions were included as well. Validated Greek versions of the scales were used.

PERMA-Profiler (Butler \& Kern, 2016; Pezirkianidis, Stalikas, Lakioti, \& Yotsidi, 2019). PERMA-Profiler includes 23 items and assesses well-being using five pillars as conceptualised by Seligman (2011). Core subscales involve positive emotions, engagement, relationships, meaning, and accomplishment. In addition, a negative emotions subscale and physical health subscale is included, as well as a single item measuring loneliness and a single item evaluating overall happiness. Each subscale involves 3 items. Responses are provided on a 10-point Likert scale, ranging from 0 to 10 . Response options are differentiated among subscales. Following the guidelines of Butler and Kern (2016), an overall well-being scored was computed in the present study, comprised of the five core subscales and the overall happiness item $(\alpha=.91)$. A total mean score was calculated for each subscale, with higher scores reflecting higher overall well-being (see Table 2).

CD-RISC (Connor \& Davidson, 2003). CD-RISC comprises of 25 items ( $\alpha$ $=.95)$ that measure psychological resilience. Five components are assessed, namely personal competence, tolerance of negative affect, positive acceptance of change and secure relationships, control, and spiritual influences. Responses are given on a 5-point Likert scale, ranging from 0 (not true at all) to 4 (true nearly all of the time). A total mean score was calculated for all 25 items, with higher scores indicating higher psychological resilience (see Table 3).

Table 2. Reliability analysis and sample items of PERMA-profiler.

\begin{tabular}{|c|c|c|}
\hline Subscales & Cronbach's a & Sample Items \\
\hline 1) Positive emotions & .78 & "In general, to what extent do you feel contented?" \\
\hline 2) Engagement & .62 & $\begin{array}{l}\text { "In general, to what extent do you feel excited and interested } \\
\text { in things?" }\end{array}$ \\
\hline 3) Relationships & .73 & $\begin{array}{l}\text { "To what extent do you receive help and support from others } \\
\text { when you need it?" }\end{array}$ \\
\hline 4) Meaning & .76 & $\begin{array}{l}\text { "In general, to what extent do you lead a purposeful and mea- } \\
\text { ningful life?" }\end{array}$ \\
\hline 5) Accomplishment & .80 & "How often are you able to handle your responsibilities?" \\
\hline 6) Negative Emotions & .77 & "In general, how often do you feel anxious?" \\
\hline 7) Physical Health & .85 & "How satisfied are you with your current physical health?" \\
\hline
\end{tabular}

Table 3. Reliability analysis and sample items of CD-RISC.

\begin{tabular}{|c|c|c|c|}
\hline Subscales & $n$ of Items & Cronbach's a & Sample Items \\
\hline 1) Personal competence & 8 & .88 & "When things look hopeless, I don't give up" \\
\hline 2) Tolerance of negative affect & 7 & .84 & "Under pressure, I focus and think clearly" \\
\hline $\begin{array}{l}\text { 3) Positive acceptance of } \\
\text { change/Secure relationships }\end{array}$ & 5 & .86 & $\begin{array}{l}\text { "I tend to bounce back after illness or } \\
\text { hardship" }\end{array}$ \\
\hline 4) Control & 3 & .70 & "I have a strong sense of purpose" \\
\hline 5) Spiritual influences & 2 & .74 & "Things happen for a reason" \\
\hline
\end{tabular}


Family resilience questionnaire (Walsh, 2015). The family resilience questionnaire includes 32 items $(\alpha=.95)$ that assess family resilience under stressful situations. The current study used the Greek version of the family resilience questionnaire as validated by Bouka (2016), where six components of family resilience are proposed: Coping strategies, problem-solving communication, structural models, beliefs system, social support networks, and financial support sources. Responses are provided on a 5-point Likert scale, ranging from 1 (rarely/never) to 5 (almost always). Mean scores were calculated with higher scores reflecting higher family resilience (see Table 4).

\subsection{Procedure}

The questionnaire battery was designed and distributed online via Google Forms. The sample was collected online through social media and email correspondence. A snowball sampling technique was applied, where the researchers first invited their acquaintances to participate in the study and then, their acquaintances asked individuals from their social milieu to participate in the survey. Eligibility criteria included being over 18 years old and a mother or father. Prior to the presentation of the questionnaire battery, all respondents were provided with an explanatory statement written consent was sought. The explanatory statement informed participants about the aim of the research, as well as about the survey procedure and duration. Also, it was explicitly stated that respondents have the right to withdraw from the study at any time with no consequences and that the confidentiality and anonymity of data is assured.

\section{Results}

\subsection{Assumption Testing}

Hypotheses 1 and 2. Multiple linear regression requires independence of errors, absence of multicollinearity, linearity, homoscedasticity of residuals, approximately normally distributed residuals and no significant outliers/influential

Table 4. Reliability analysis and sample items of the family resilience questionnaire.

\begin{tabular}{|c|c|c|c|}
\hline Subscales & $n$ of Items & Cronbach's $\alpha$ & Sample Items \\
\hline 1) Coping strategies & 9 & .90 & $\begin{array}{l}\text { "We take an active attitude and persevere in } \\
\text { our efforts to face and resolve problems" }\end{array}$ \\
\hline $\begin{array}{l}\text { 2) Problem-solving } \\
\text { communication }\end{array}$ & 7 & .90 & $\begin{array}{l}\text { "We can show understanding, accept } \\
\text { differences, and avoid negative judgments" }\end{array}$ \\
\hline 3) Structural models & 6 & .78 & $\begin{array}{l}\text { "We face our difficulties as a couple/family, } \\
\text { rather than separately" }\end{array}$ \\
\hline 4) Beliefs system & 5 & .73 & $\begin{array}{l}\text { "Our sufferance has made us more } \\
\text { understanding and willing to help others" }\end{array}$ \\
\hline 5) Social support networks & 2 & .53 & $\begin{array}{l}\text { "We can trust in the help of relatives, friends, } \\
\text { neighbors, and the community" }\end{array}$ \\
\hline $\begin{array}{l}\text { 6) Financial support } \\
\text { sources }\end{array}$ & 2 & .23 & $\begin{array}{l}\text { "We have economic security to be able to } \\
\text { overcome difficult times" }\end{array}$ \\
\hline
\end{tabular}


points (Tabachnick \& Fidell, 2013). Durbin-Watson's test suggested independence of errors for model $1(\mathrm{D}-\mathrm{W}$ statistic $=1.99)$ and model $2(\mathrm{D}-\mathrm{W}$ statistic $=$ 1.70), whilst no multicollinearity was observed for both models (all VIF values < 10). Moreover, a scatterplot of standardized residuals against standardized predicted values and partial regression plots revealed linear relationships and homoscedasticity for model 1 and model 2. In addition, a histogram and a normal $\mathrm{P}-\mathrm{P}$ plot of standardized residuals revealed approximately normally distributed residuals for both models.

Regarding the presence of outliers, only two outliers were detected, one for model $1(\mathrm{ID}=18$, standardized residual $=-3.53)$ and one for model $2($ ID $=19$, standardized residual $=-3.29)$, while Cook's distance values for both models suggested that no case influenced significantly the ability of the model to predict all cases (all values $<1$ ). Concerning multivariate outliers, the maximum acceptable value for Mahalanobis distance was 20.52 at a significance level of $p$ $<.001$. Only one case exceeded this criterion in both models (ID = 23; Mahalanobis distance $=22.12$ ). The researchers decided to retain the outliers in the analyses, as Stevens (2002) advised that outliers with Cook's distance values $<1$ should not be deleted, because they are not expected to have a significant impact on the model.

Hypotheses 3 to 5 . Independent samples $t$-tests require approximately normally distributed data, no extreme outliers, and homogeneity of variances (Field, 2013). Shapiro-Wilk's test of normality was consulted for the male group ( $n=$ 20). Considering that Shapiro-Wilk's test may denote even minor deviations from normality as statistically significant in large group sizes $(n>30)$, normal Q-Q plots were advised for the female group $(n=63)$ (Field, 2013). Shapiro-Wilk's test indicated approximately normally distributed data for the male group in family resilience $(p=.76)$, parental well-being $(p=.85)$, and parental resilience $(p=.81)$, while normal Q-Q plots showed approximately normally distributed data for the female group in all three dependent variables. Also, no extreme outliers were identified in both groups for family resilience, parental well-being, and parental resilience. Finally, heterogeneity of variances was observed in family resilience $(p=.005)$, parental well-being $(p=.007)$, and parental resilience $(p=.020)$. Consequently, corrected degrees of freedom were used to account for this violation.

\subsection{Hypothesis Testing}

Hypothesis 1. A hierarchical multiple regression analysis was conducted to examine if family resilience would be identified as a statistically significant predictor of parental well-being. The predictor variables included the family resilience factors. The criterion variable was well-being. Coping strategies was entered on step 1 and the rest of the predictor variables were entered on step 2 . The order of the predictors was based on their strength of correlation with the outcome variable. Coping strategies showed the strongest correlation with the crite- 
rion variable $(r=.51)$, whereas the rest of the predictors displayed approximately the same moderate levels of association with the outcome variable.

The analysis indicated a statistically significant model on step $1[F(1,81)=$ $28.28, p<.001]$ and on step $2[F(5,77)=6.69, p<.001]$. The percentage of variance in well-being accounted for by step 1 was $25 \%\left(R^{2}=.26\right.$, adjusted $\left.R^{2}=.25\right)$ and increased marginally to $26 \%$ on step $2\left(R^{2}=.30\right.$, adjusted $\left.R^{2}=.26\right)$. Change statistics indicated that the additional $.8 \%$ of the variance explained in well-being on step 2 was not statistically significant, $F_{\text {change }}(4,77)=1.22, p=.31$. Considering the individual contribution of predictors, coping strategies was a statistically significant predictor on step $1(p<.001)$ and step $2(p=.002)$. None of the other predictor variables reached statistical significance on step 2 (see Table 5).

Hypothesis 2. A hierarchical multiple regression analysis was performed to examine if family resilience would emerge as a statistically significant predictor of parental resilience. Similarly, coping strategies was entered on step 1 and the rest of the predictor variables were entered on step 2. The order of the predictors was based on their strength of correlation with the outcome variable. Coping strategies showed the strongest correlation with the criterion variable $(R=.51)$, while the rest of the predictors displayed approximately the same moderate levels of association with the outcome variable.

The analysis indicated a statistically significant model on step $1[F(1,81)=$ $28.14, p<.001]$ and on step $2[F(5,77)=7.17, p<.001]$. The percentage of variance in parental resilience accounted for by step 1 was $25 \%\left(R^{2}=.26\right.$, adjusted $\left.R^{2}=.25\right)$ and increased slightly to $27 \%$ on step $2\left(R^{2}=.32\right.$, adjusted $\left.R^{2}=.27\right)$. Change statistics indicated that the additional $2 \%$ of the variance explained in parental resilience on step 2 was not statistically significant, $F_{\text {change }}(4,77)=1.67$,

Table 5. Hierarchical multiple regression with parental well-being as the criterion variable and coping strategies (CS), problem-solving communication (PSC), structural models (SM), beliefs system (BS), and social support networks (SSN) as predictor variables $(n=$ $83)$.

\begin{tabular}{cccc}
\hline Predictor & $B(95 \% \mathrm{CI})$ & $S E_{B}$ & $\beta$ \\
\hline Step 1 & & \\
Constant & $3.57(2.22,4.92)$ & .68 & $.51^{* *}$ \\
CS & $.93(.58,1.27)$ & .17 & \\
& Step 2 & & $.64^{*}$ \\
Constant & $3.57(2.05,5.09)$ & .76 & .13 \\
CS & $1.17(.46,1.87)$ & .35 & -.14 \\
PSC & $.20(-.32, .72)$ & .26 & -.24 \\
SM & $-.27(-.90, .37)$ & .32 & .14 \\
BS & $-.41(-.94, .13)$ & .27 & .17 \\
SSN & $.22(-.12, .55)$ & & \\
\hline
\end{tabular}

Note. ${ }^{*} p<.01,{ }^{* *} p<.001 ; B=$ Unstandardized regression coefficient; $\mathrm{CI}=$ Confidence Intervals; $S E_{B}=$ Standard error of the regression coefficient. $\beta=$ Standardized regression coefficient. 
$p=.16$. Regarding the individual contribution of predictors, coping strategies was a statistically significant predictor on step $1(p<.001)$ and step $2(p=.001)$. None of the other predictor variables reached statistical significance on step 2 (see Table 6).

Hypotheses 3 to 5 . An independent samples $t$-test was performed to assess, if there is a statistically significant difference in family resilience (H3), parental well-being (H4), and parental resilience (H5) between fathers $(n=20)$ and mothers $(n=63)$. The descriptive analysis showed marginal differences in family resilience between fathers $(M=3.80, S D=.30)$ and mothers $(M=3.78, S D$ $=.65)$. Similarly, fathers reported slightly higher well-being $(M=7.38, S D=.58$ vs $M=7.04, S D=1.27)$ and resilience levels than mothers $(M=2.67, S D=.39$ vs $M=2.63, S D=.74$; see Figure 1).

Table 6. Hierarchical multiple regression with parental resilience as the criterion variable and coping strategies (CS), problem-solving communication (PSC), structural models (SM), beliefs system (BS), and social support networks (SSN) as predictor variables $(n=$ 83).

\begin{tabular}{cccc}
\hline Predictor & \multicolumn{1}{c}{$B(95 \% \mathrm{CI})$} & $S E_{B}$ & $\beta$ \\
\hline Constant & $.58(-.20,1.36)$ & .39 & \\
CS & $.54(.34, .74)$ & .10 & $.51^{* *}$ \\
& \multicolumn{2}{c}{ Step 1} \\
Constant 2 & .44 & \\
CS & $.52(-.35,1.39)$ & .20 & $.66^{*}$ \\
PSC & $.70(.29,1.11)$ & .15 & -.12 \\
SM & $-.11(-.40, .19)$ & .18 & -.13 \\
BS & $-.14(-.51, .22)$ & .15 & -.090 \\
SSN & $-.088(-.40, .22)$ & .096 & .21 \\
\hline
\end{tabular}

Note. ${ }^{\star} p<.01,{ }^{* *} p<.001 ; B=$ Unstandardized regression coefficient; $\mathrm{CI}=$ Confidence Intervals; $S E_{B}=$ Standard error of the regression coefficient. $\beta=$ Standardized regression coefficient.

\section{Gender differences}

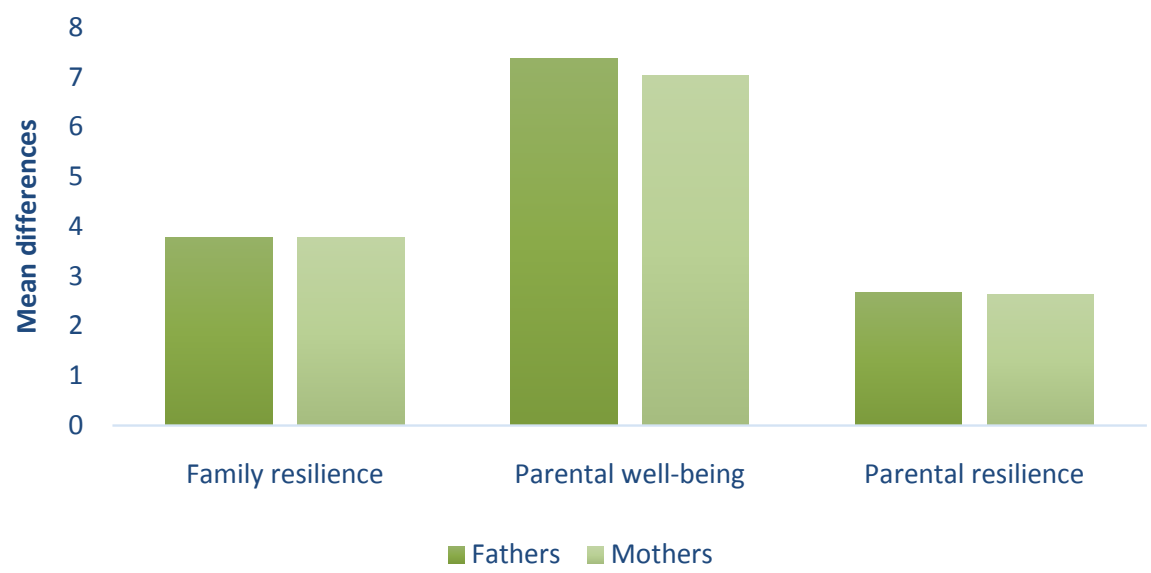

Figure 1. Differences in family resilience, parental well-being, and parental resilience between fathers and mothers. 
The independent samples $t$-test suggested a non-statistically significant difference in family resilience, $t(69.95)=.16, M d f=.017,95 \%$ CI $[-.19,-.23], p$ $=.87, d=.04$, parental well-being, $t(71.13)=1.65, M d f=.34,95 \%$ CI $[-.071, .75]$, $p=.10, d=.39$, and resilience between fathers and mothers, $t(61.70)=.28, M d f$ $=.036,95 \% \mathrm{CI}[-.22, .29], p=.78, d=.07$.

\section{Discussion}

The aim of the present study was to explore the associations between family resilience, parental well-being and parental resilience among Greek parents. To the best of our knowledge, there are no other studies investigating the relationship of family resilience with parental well-being and resilience in a Greek family context. Moreover, the limited number of studies available on FWB and parental resilience have been conducted in non-Greek populations, and have examined associations between family resilience factors and parental mental health (e.g. Eilersen et al., 2015), or parental well-being in response to adverse events (e.g. parental well-being and daily stress; Gerstein et al., 2009).

Our study tested five hypotheses. Concerning hypothesis 1 , results indicated that the only family resilience factor that predicted significantly parental well-being is the coping strategies that a family uses. However, the rest of the aspects of family resilience, e.g. problem-solving communication and beliefs system, did not emerge as significant predictors of parental well-being. Therefore, H1 received partial empirical support. The current findings are partly supported by the study of Grant and colleagues (2013), who found that in terms of family resilience, parents utilised social resources and employed coping strategies. Specifically, parents' highest protective factor was social resources (i.e. planned future) and their most frequently used coping strategy was emotion-focused (i.e. acceptance). Nevertheless, in the present study only the coping strategies of the family emerged as a significant positive predictor of parental well-being. Also, it is important to mention that Grant and colleagues (2013) reported a negative relationship between coping strategies and parental well-being, suggesting that parents who used coping strategies at a higher level were more likely to report lower well-being. The difference in the direction of the association may be explained by the qualitative difference and severity of the adverse events experienced between the two study samples. Parents of children diagnosed with disabilities consistently report reduced resilience in the literature and are known to experience greater practical, emotional and financial difficulties over time compared to parents of healthy children (Nidiffer \& Kelly, 1983).

Considering the Greek family context and exposure to life challenges experienced more commonly by families (that is, more commonly than disability or rare and life-threatening diseases), it is important to interpret the results of $\mathrm{H} 1$ in comparison to a study employing a more representative sample (compared to the sample of Grant et al., 2013). One such example includes a qualitative study investigating risks and parental coping strategies during economic recession (i.e. 
high unemployment, austerity measures) among Finnish families (Lindberg, Nygård, \& Nyqvist, 2018). The results of this study indicated that parents employed both inner and external coping strategies. In terms of inner coping strategies, sense of coherence was the most important strategy in holding life together on a day-to-day basis. In coping with risk, external strategies, considered to be equally important were identified including economical arrangements, utilising social networks, and prioritising means and time.

In regard to hypothesis 2 , the findings indicate once more that the coping strategies, that the family uses, were the only significant predictor of parental resilience. Nevertheless, as in $\mathrm{H} 1$, other family protective factors against adversity did not predict significantly parental resilience and thus, $\mathrm{H} 2$ was partially supported. However, it is not possible to juxtapose the results of $\mathrm{H} 2$ to past findings, due to the lack of relevant research. Overall, the findings on coping strategies being the only significant predictor of parental well-being and resilience ( $\mathrm{H} 1$ and $\mathrm{H} 2$ ), may best be considered qualitatively and in relation to Lindberg and colleagues' (2018) observations on coping strategies. Lindberg and colleagues (2018) define sense of coherence in terms of the way in which individuals cope with everyday life considering the stress and adversity they face, and in terms of inner and external risks influencing the family unit and respective strategies (i.e. strategies involving individual ways of coping, and strategies such as employment and education accordingly; Antonovsky, 1979; Leiss, Beck, Ritter, \& Lash, 1995). Consequently, one possible interpretation of the current results is that due to the limited support by the government in Greece in times of economic hardship (e.g. social benefits; Zambarloukou, 2015), it is likely that similarly to Finnish parents, Greek parents rely on inner coping strategies (such as that of sense of coherence) to persevere in times of adversity, above and beyond all other resilience factors described by Walsh's $(2003,2012)$ resilience framework.

Regarding hypothesis 3 to 5, preliminary analyses showed that fathers displayed slightly higher perceived family resilience (H3), parental well-being (H4), and parental resilience (H5) than mothers. Nonetheless, these differences did not reach statistical significance and thus, $\mathrm{H} 3$ to $\mathrm{H} 5$ were not supported. Although there is no relevant research on parental differences in family resilience, past research has shown that mothers display significantly poorer well-being than fathers. Indicatively, it has been documented that mothers report higher anxiety and depression levels (Bitsika et al., 2013), as well as greater strain in terms of role demands and parental strain (Scott \& Alwin, 2015). Also, concerning parental resilience, the majority of studies have focused on maternal resilience with few examining parental resilience in both parents (e.g. Brennan, Le Brocque, \& Hammen, 2003; Easterbrooks, Chaudhuri, Bartlett, \& Copeman, 2011). However, Bitsika and colleagues (2013) reported no differences in parental resilience between mothers and fathers.

\section{Limitations}

The findings presented should be interpreted with caution due to certain me- 
thodological limitations associated with the present study. Concerning the research design of the study, data was collected employing a snowball sampling method. In spite this, being a frequently used method in psychological research and deemed appropriate for reaching hidden populations (e.g. used for studying sensitive matters; Waters, 2013), it is likely that using social networks may have indirectly led to underrepresentation of specific populations (e.g. socioeconomically disadvantaged families). Also, although the analyses conducted for $\mathrm{H} 1$ and $\mathrm{H} 2$ examined the predictive power of family resilience on parental well-being and resilience, causal attributions cannot be inferred due to the cross-sectional design of the study (e.g. Reichenheim \& Coutinho, 2010). Therefore, the reader is advised to focus on the correlational aspect of those results. In addition, the researchers did not use the subscales of the PERMA-Profiler (Butler \& Kern, 2016) and CD-RISC (Connor \& Davidson, 2003) and calculated total scores instead. It could be assumed that the employment of subscales might have led to the identification of additional relationships and/or differences.

Proceeding with issues observed during the analyses of the data, in consistence with previous studies (e.g. Grant et al., 2013), an underrepresentation of fathers was observed. It is likely that increased father participation-or a balanced gender ratio-may have yielded different results with regards to $\mathrm{H} 3$ to H5. Finally, the findings suggested no significant differences in family resilience, parental well-being, and parental resilience between fathers and mothers. Nevertheless, a moderate effect was identified for $\mathrm{H} 4$ (parental well-being differences), which suggests that the non-significance of the results may be attributed to the lack of adequate statistical power (e.g. Perugini, Gallucci, \& Costantini, 2018), especially when considering evidence supporting the presence of decreased maternal well-being (Bitsika et al., 2013).

\section{Directions for Future Research}

Taking into account the methodological limitations of the present study, as well as the partial support and disconfirmation of research hypotheses, it is considered appropriate to focus on the discussion of future research directions and refrain from the proposal of practical implications. Firstly, participant recruitment should consider targeting individuals from different socioeconomic backgrounds to ensure that the research is as representative as possible. Also, longitudinal research designs could lead to the establishment of causal attributions as to the importance of family resilience on parental well-being and as a result, propose targeted interventions that could ameliorate family well-being in the most efficient manner.

Furthermore, future researchers should consider building on these findings by continuing research on parental resilience, well-being and coping strategies. The coping strategies of the family were found to be a predictor of parental well-being and resilience and have been highlighted as a key family resilience factor in past research. Focusing on coping strategies of the family in times of adversity, Lind- 
berg and colleagues (2018) differentiated between inner (e.g. sense of coherence) and external (e.g. employment) strategies that are likely to be relevant in the Greek context too. For instance, a qualitative approach (e.g. interviews) may be appropriate to explore parental inner and external coping strategies, reliance on each strategy, and perceived reliability and efficacy. Finally, after the accumulation of relevant rigorous research, it would be valuable, both in terms of research and individual welfare, to design positive parental interventions and assess their outcomes. Also, family-oriented interventions should focus on enhancing family adaptive processes, values, and behaviours and examine their effects on both family well-being and individual resilience and well-being of both parents and children.

\section{Conclusion}

To conclude, the current research attempted to make a multifaceted contribution to the literature on family resilience, parental resilience and well-being. First, a sample of Greek families was employed, which allowed for an exploration of the associations among the aforementioned constructs in the under-researched Greek context. Furthermore, the research was conducted among parents of healthy children, which was also a gap identified in the literature (non-Greek populations; Grant et al., 2013; Ilias, Cornish, Park, Toran, \& Golden, 2019). Moreover, although negligible differences were found between mothers and fathers in terms of family resilience, parental resilience and parental well-being, the present research sought to explore gender differences and in particular, includes the paternal experience as it has been underexplored by past studies. Lastly, coping strategies of the family against adversities were revealed as the most important resilience factor possibly indicating cross-cultural differences between Greek and other European populations. The researchers aspire that the current study will act as a source of motivation for other scholars with the aim of advancing research and improve the functioning and well-being of the family unit. Past research has focused on the resilience of migrant children in Greece (e.g. Michail, 2012) or student resilience among Greek students (e.g. Hatzichristou et al., 2017).

\section{Conflicts of Interest}

The authors declare no conflicts of interest regarding the publication of this paper.

\section{References}

Anagnostaki, L., Pavlopoulos, V., Obradović, J., Masten, A., \& Motti-Stefanidi, F. (2016). Academic Resilience of Immigrant Youth in Greek Schools: Personal and Family Resources. European Journal of Developmental Psychology, 13, 377-393. https://doi.org/10.1080/17405629.2016.1168738

Antonovsky, A. (1979). Health, Stress and Coping. San Francisco, CA: Jossey-Bass.

Bitsika, V., \& Sharpley, C. (2004). Stress, Anxiety and Depression among Parents of 
Children with Autism Spectrum Disorder. Australian Journal of Guidance and Counselling, 14, 151-161. https://doi.org/10.1017/S1037291100002466

Bitsika, V., Sharpley, C., \& Bell, R. (2013). The Buffering Effect of Resilience upon Stress, Anxiety and Depression in Parents of a Child with an Autism Spectrum Disorder Disorder. Journal of Developmental and Physical Disabilities, 25, 533-543. https://doi.org/10.1007/s10882-013-9333-5

Black, K., \& Lobo, M. (2008). A Conceptual Review of Family Resilience Factors. Journal of Family Nursing, 14, 33-55. https://doi.org/10.1177/1074840707312237

Bonebright, C., Clay, D., \& Ankenmann, R. (2000). The Relationship of Workaholism with Work-Life Conflict, Life Satisfaction, and Purpose in Life. Journal of Counseling Psychology, 47, 469-477. https://doi.org/10.1037/0022-0167.47.4.469

Bouka, C. (2016). The Pychometric Properties of the Family Resilience Questionnaire of Froma Walsh in the Greek Population.

Brennan, P., Le Brocque, R., \& Hammen, C. (2003). Maternal Depression, Parent-Child Relationships, and Resilient Outcomes in Adolescence. Journal of the American Academy of Child \& Adolescent Psychiatry, 42, 1469-1477.

https://doi.org/10.1097/00004583-200312000-00014

Brown, S., Manning, W., \& Stykes, B. (2015). Family Structure and Child Well-Being: Integrating Family Complexity. Journal of Marriage and the Family, 77, 177-190. https://doi.org/10.1111/jomf.12145

Butler, J., \& Kern, M. (2016). The PERMA-Profiler: A Brief Multidimensional Measure of Flourishing. International Journal of Wellbeing, 6, 1-48. https://doi.org/10.5502/ijw.v6i3.526

Clarke, N., McCarthy, M., Downie, P., Ashley, D., \& Andreson, V. (2009). Gender Differences on the Psychosocial Experience of Parents of Children with Cancer: A Review of the Literature. Psychooncology, 18, 515-523. https://doi.org/10.1002/pon.1515

Cohn, M., Fredrickson, B., Brown, S., Mikels, J., \& Conway, A. (2009). Happiness Unpacked: Positive Emotions Increase Life Satisfaction by Building Resilience. Emotion, 9, 361-368. https://doi.org/10.1037/a0015952

Connor, K. M., \& Davidson, J. R. (2003). Development of a New Resilience Scale: The Connor-Davidson Resilience Scale (CD-RISC). Depression and Anxiety, 18, 76-82. https://doi.org/10.1002/da.10113

Coyle, J., Nochajski, T., Maguin, E., Safyer, A., Dewit, D., \& Macdonald, S. (2009). An Exploratory Study of the Nature of Family Resilience in Families Affected by Parental Alcohol Abuse. Journal of Family Issues, 30, 1606-1623.

https://doi.org/10.1177/0192513X09339478

Crawford, J. (2011). Bringing It Together: Assessing Parenting Capacity in the Child Protection Context. Social Work Now, 47, 18-26. https://www.semanticscholar.org

Easterbrooks, M., Chaudhuri, J., Bartlett, J., \& Copeman, A. (2011). Resilience in Parenting among Young Mothers: Family and Ecological Risks and Opportunities. Children and Youth Services Review, 33, 42-50. https://doi.org/10.1016/j.childyouth.2010.08.010

Eilersen, M., Hjemdal, O., Le, T., Diseth, T., \& Reinfjell, T. (2015). Resilience Factors Play an Important Role in the Mental Health of Parents When Children Survive Acute Lymphoblastic Leukaemia. Acta Paediatrica, 105, e30-e34. https://doi.org/10.1111/apa.13232

Erickson, R. (2005). Why Emotion Matters: Sex, Gender, and the Division of Household Labor. The Journal of Marriage and Family, 67, 337-351.

https://doi.org/10.1111/j.0022-2445.2005.00120.x 
Fernandez, I., Schwartz, J., Chun, H., \& Dickson, G. (2012). Family Resilience and Parenting. In D. Becvar (Ed.), Handbook of Family Resilience (pp. 119-136). New York: Springer. https://doi.org/10.1007/978-1-4614-3917-2_8

Field, A. (2013). Discovering Statistics Using SPSS (4th ed.). Thousand Oaks, CA: Sage.

Fredrickson, B. (2001). The Role of Positive Emotions in Positive Psychology: The Broaden-and-Build Theory of Positive Emotions. The American Psychologist, 56, 218-226. https://doi.org/10.1037/0003-066X.56.3.218

Fredrickson, B., Tugade, M., Waugh, C., \& Larkin, G. (2003). What Good Are Positive Emotions in Crisis? A Prospective Study of Resilience and Emotions Following the Terrorist Attacks on the United States on September 11th, 2001. Journal of Personality and Social Psychology, 84, 365-376. https://doi.org/10.1037/0022-3514.84.2.365

Garland, E., Fredrickson, B., Kring, A., Johnson, D., Meyer, P., \& Penn, D. (2010). Upward Spirals of Positive Emotions Counter Downward Spirals of Negativity: Insights from the Broaden-and-Build Theory and Affective Neuroscience on the Treatment of Emotion Dysfunctions and Deficits in Psychopathology. Clinical Psychology Review, 30, 849-864. https://doi.org/10.1016/j.cpr.2010.03.002

Gavidia-Payne, S., Denny, B., Davis, K., Francis, A., \& Jackson, M. (2015). Parental Resilience: A Neglected Construct in Resilience Research. Clinical Psychologist, 19, 111-121. https://doi.org/10.1111/cp.12053

Gendron, M. (2010). Defining Emotion: A Brief History. Emotion Review, 2, 371. https://doi.org/10.1177/1754073910374669

Gerstein, E., Crnic, K., Blacher, J., \& Baker, B. (2009). Resilience and the Course of Daily Parenting Stress in Families of Young Children with Intellectual Disabilities. Journal of Intellectual Disability Research, 53, 981-997. https://doi.org/10.1111/j.1365-2788.2009.01220.x

Grant, S., Cross, E., Wraith, J., Jones, S., Mahon, L., Lomax, M., Hare, D. et al. (2013). Parental Social Support, Coping Strategies, Resilience Factors, Stress, Anxiety and Depression Levels in Parents of Children with MPS III (Sanfilippo Syndrome) or Children with Intellectual Disabilities (ID). Journal of Inherited Metabolic Disease, 36, 281-291. https://doi.org/10.1007/s10545-012-9558-y

Gudmundsdottir, E., Schirren, M., \& Boman, K. (2011). Psychological Resilience and Long-Term Distress in Swedish and Icelandic Parents' Adjustment to Childhood Cancer. Acta Oncologica, 50, 373-380. https://doi.org/10.3109/0284186X.2010.489572

Hatzichristou, C., Lianos, P., \& Lampropoulou, A. (2017). Cultural Construction of Promoting Resilience and Positive School Climate during Economic Crisis in Greek Schools. International Journal School \& Educational Psychology, 5, 192-206. https://doi.org/10.1080/21683603.2016.1276816

Howick, J., Kelly, P., \& Kelly, M. (2019). Establishing a Causal Link between Social Relationships and Health Using the Bradford Hill Guidelines. Population Health, 8, 1-9. https://doi.org/10.1016/j.ssmph.2019.100402

Ilias, K., Cornish, K., Kummar, A., Park, M., \& Golden, K. (2018). Parenting Stress and Resilience in Parents of Children with Autism Spectrum Disorder (ASD) in Southeast Asia: A Systematic Review. Frontiers in Psychology, 9, 280. https://doi.org/10.3389/fpsyg.2018.00280

Ilias, K., Cornish, K., Park, M., Toran, H., \& Golden, K. (2019). Risk and Resilience among Fathers and Mothers of Primary School Age Children with ASD in Malaysia: A Qualitative Constructive Grounded Theory Approach. Frontiers in Psychology, 9, 2275. https://doi.org/10.3389/fpsyg.2018.02275

Isaacs, S., Roman, N., \& Savahl, S. (2018). The Development of a Family Resilience- 
Strengthening Programme for Families in a South African Rural Community. Journal of Community Psychology, 1, 1-20.

Jordan, L., \& Graham, E. (2012). Resilience and Well-Being among Children of Migrant Parents in South-East Asia. Child Development, 83, 1672-1688. https://doi.org/10.1111/j.1467-8624.2012.01810.x

Keyes, C. (2002). The Mental Health Continuum: From Languishing to Flourishing in Life. Journal of Health and Social Behavior, 43, 207-222. https://doi.org/10.2307/3090197

Leiss, W., Beck, U., Ritter, M., \& Lash, S. (1995). Risk Society, towards a New Modernity. Canadian Journal of Oncology, 19, 544. https://doi.org/10.2307/3341155

Lester, P., \& Flake, E. (2013). How Wartime Military Service Affects Children and Families. Future of Children, 23, 121-141. https://doi.org/10.1353/foc.2013.0015

Lester, P., Liang, L., Milburn, N., Mogil, C., Woodward, K., Nash, W., Saltzman, W. et al. (2016). Evaluation of a Family-Centered Preventive Invervention for Military Families: Parent and Child Longitudinal Outcomes. Journal of the American Academy of Child and Adolescent Psychiatry, 55, 14-24. https://doi.org/10.1016/j.jaac.2015.10.009

Lindberg, M., Nygård, M., \& Nyqvist, F. (2018). Risks, Coping Strategies and Family Wellbeing: Evidence from Finland. International Journal of Sociology and Social Policy, 38, 1116-1132. https://doi.org/10.1108/IJSSP-04-2018-0064

López, E., Musitu, G., \& Herrero, J. (2005). The Role of Family Communication and School Adjustment on Adolescent Mental Health. Mental Health, 28, 81-89. https://www.researchgate.net

Luthar, S., Cicchetti, D., \& Becker, B. (2000). The Construct of Resilience: A Critical Evaluation and Guidelines for Future Work. Child Development, 71, 543-562.

https://doi.org/10.1111/1467-8624.00164

Macdonald, M., Chilibeck, G., Affleck, W., \& Cadell, S. (2010). Gender Imbalance in Paediatric Palliative Care Research Samples. Palliative Medicine, 24, 435-444. https://doi.org/10.1177/0269216309354396

Mackay, R. (2003). Family Resilience and Good Child Outcomes: An Overview of the Research Literature. Social Policy Journal of New Zealand, 20, 98-118.

MacPhee, D., Lunkenheimer, E., \& Riggs, N. (2015). Resilience as Regulation of Developmental and Family Processes. Family Relations, 64, 153-175. https://doi.org/10.1111/fare.12100

Mandleco, B., \& Peery, J. (2000). An Organising Framework for Conceptualising Resilience in Children. Journal of Adolescent Psychiatric Nursing, 13, 99-112. https://doi.org/10.1111/j.1744-6171.2000.tb00086.x

Martinviita-Hietala, M., Joskitt, L., Ebeling, H., Yliherva, A., \& Moilanen, I. (2018). Parenthood and Stress of Caring for Infants in Different Circumstances in Finland. Early Child Development and Care, 1, 1-15.

Masten, A. (2001). Ordinary Magic: Resilience Processes in Development. American Psychologist, 56, 227-238. https://doi.org/10.1037/0003-066X.56.3.227

Masten, A., \& Cicchetti, D. (2016). Resilience in Development: Progress and Transformation. In D. Cicchetti (Ed.), Developmental Psychopathology (pp. 271-333). Hoboken, NJ: Wiley. https://doi.org/10.1002/9781119125556.devpsy406

Matjasko, J., Vivolo-Kantor, A., Henry, D., Gorman-Smith, D., \& Schoeny, M. (2013). The Relationship between a Family-Focused Preventive Intervention, Parenting Practices, and Exposure to Violence during the Transition to Adolescence: Testing a Mediation Model. Journal of Aggression, Maltreatment \& Trauma, 22, 45-66. 
https://doi.org/10.1080/10926771.2013.743947

Merz, E., Consedine, N., Schulze, H., \& Schuengel, C. (2009). Well-Being of Adult Children and Ageing Parents: Associations with Intergenerational Support and Relationship Quality. Ageing \& Society, 29, 783-802. https://doi.org/10.1017/S0144686X09008514

Michail, D. (2012). Social Development and Transnational Households: Resilience and Motivation for Albanian Immigrants in Greece in the Era of Economic Crisis. Southeast European and Black Sea Studies, 13, 265-279. https://doi.org/10.1080/14683857.2013.789673

Moore, G., \& Neiderhiser, J. (2014). Behavioral Genetic Approaches and Family Theory. Journal of Family Theory \& Review, 6, 18-30. https://doi.org/10.1111/jftr.12028

Nelson, K., Kushlev, K., English, T., Dunn, E., \& Lyubomirsky, S. (2012). In Defence of Parenthood: Children Are Associated with More Joy than Misery. Psychological Science, 24, 3-10. https://doi.org/10.1177/0956797612447798

Newland, L. (2015). Family Well-Being, Parenting, and Child Well-Being: Pathways to Healthy Adjustment. Clinical Psychologist, 19, 3-14. https://doi.org/10.1111/cp.12059

Nidiffer, F., \& Kelly, T. (1983). Developmental and Degenerative Patterns Associated with Cognitive, Behavioural and Motor Difficulties in the Sanfilippo Syndrome: An Epidemiological Study. Journal of Mental Deficiency Research, 27, 185-203. https://doi.org/10.1111/j.1365-2788.1983.tb00291.x

Osofsky, J., \& Chartrand, M. (2013). Military Children from Birth to Five Years. Future of Children, 23, 61-77. https://doi.org/10.1353/foc.2013.0011

Perugini, M., Gallucci, M., \& Costantini, G. (2018). A Practical Primer to Power Analysis for Simple Experimental Designs. International Review of Social Psychology, 31, 20. https://doi.org/10.5334/irsp.181

Pezirkianidis, C., Stalikas, A., Lakioti, A., \& Yotsidi, V. (2019). Validating a Multidimensional Measure of Wellbeing in Greece: Translation, Factor Structure, and Measurement Invariance of the PERMA Profiler. Current Psychology, 1-18.

https://doi.org/10.1007/s12144-019-00236-7

Polenick, C., DePasquale, N., Eggebeen, D., Zarit, S., \& Fingerman, K. (2016). Relationship Quality between Older Fathers and Middle-Aged Children: Associations with Both Parties' Subjective Well-Being. The Journals of Gerontology Series B, 73, gbw094. https://doi.org/10.1093/geronb/gbw094

Powel, J., Goodyear, M., Maybery, D., Reupert, A., O’Hanlon, B., Cuff, R., \& Perlesz, A. (2015). Family Resilience in Families Where a Parent Has Mental Illness. Journal of Social Work, 1-17. https://doi.org/10.1177/1468017314568081

Reichenheim, M., \& Coutinho, E. (2010). Measures and Models for Causal Inference in Cross-Sectional Studies: Arguments for the Appropriateness of the Prevalence Odds Ratio and Related Logistic Regression. BMC Medical Research Methodology, 10, 66. https://doi.org/10.1186/1471-2288-10-66

Reker, G., \& Chamberlain, K. (2000). Exploring Existential Meaning: Optimizing Human Development across the Life Span. Thousand Oaks, CA: Sage.

Roland, J. (2016). Chronic Illness and the Family Cycle. In M. McGoldrick, B. Carter, \& N. Preto (Eds.), The Expanded Family Cycle: Individual, Family, and Social Perspectives (pp. 430-450). London: Pearson. https://www.pearsonhighered.com

Ryan, R., \& Deci, E. (2000). Self-Determination Theory and the Facilitation of Intrinsic Motivation, Social Development, and Wellbeing. American Psychologist, 55, 68-78. https://doi.org/10.1037/0003-066X.55.1.68

Ryan, R., \& Deci, E. (2001). On Happiness and Human Potentials: A Review on Hedonic 
and Eudaimonic Wellbeing. Annual Review of Psychology, 52, 141-166.

https://doi.org/10.1146/annurev.psych.52.1.141

Ryff, C., Singer, B., \& Love, G. (2004). Positive Health: Connecting Well-Being with Biology. Philosophical Transactions of the Royal Society, 359, 1383-1394.

https://doi.org/10.1098/rstb.2004.1521

Schaufeli, W., Bakker, A., \& Salanova, M. (2006). The Measurement of Work Engagement with a Short Questionnaire: A Cross-National Study. Educational and Psychological Measurement, 66, 701-716. https://doi.org/10.1177/0013164405282471

Scott, J., \& Alwin, D. (2015). Gender Differences in Parental Strain: Parental Role of Gender Role? Journal of Family Issues, 10, 482-503.

https://doi.org/10.1177/019251389010004004

Seligman, M. (2011). Flourish: A Visionary New Understanding of Happiness and Well-Being. New York: Free Press.

Simon, J., Murphy, J., \& Smith, S. (2005). Understanding and Fostering Family Resilience. Family Journal, 13, 427-436. https://doi.org/10.1177/1066480705278724

Smith, M. (2003). Parental Mental Health: Disruptions to Parenting and Outcomes for Children. Child and Family Social Work, 9, 3-11.

https://doi.org/10.1111/j.1365-2206.2004.00312.x

Southwick, S., Bonanno, G., Masten, A., Panter-Brick, C., \& Yehuda, R. (2014). Resilience Definitions, Theory, and Challenges: Interdisciplinary Perspectives. European Journal of Psychotraumatology, 5, 25338. https://doi.org/10.3402/ejpt.v5.25338

Steger, M. (2012). Experiencing Meaning in Life: Optimal Functioning at the Nexus of Spirituality, Psychopathology, and Wellbeing. In P. Wong (Ed.), The Human Quest for Meaning (pp. 165-184). New York: Routledge.

Steger, M., \& Shin, J. (2010). The Relevance of the Meaning in Life Questionnaire to Therapeutic Practice: A Look at the Initial Evidence. International Forum for Logotherapy, 33, 95-104.

Stevens, J. P. (2002). Applied Multivariate Statistics for the Social Sciences (4th ed.). Hillsdale, NJ: Erlbaum.

Stone, P. (2007). Opting Out? Why Women Really Quit Careers and Head Home. Berkeley, CA: University of California Press. https://doi.org/10.1525/9780520941793

Swartz, T. (2009). Intergenerational Family Relations in Adulthood: Patterns, Variations, and Implications in the Contemporary United States. Annual Review of Sociology, 35, 191-212. https://doi.org/10.1146/annurev.soc.34.040507.134615

Tabachnick, B. G., \& Fidell, L. S. (2013). Using Multivariate Statistics (6th ed.). Upper Saddle River, NJ: Pearson Education.

Thomas, P., Liu, H., \& Umberson, D. (2017). Family Relationships and Well-Being. Innovation in Aging, 1, igx025. https://doi.org/10.1093/geroni/igx025

Tian, L., Liu, L., \& Shan, N. (2018). Parent-Child Relationships and Resilience among Chinese Adolescents: The Mediating Role of Self-Esteem. Frontiers in Psychology, 9, 1030. https://doi.org/10.3389/fpsyg.2018.01030

Tugade, M., \& Fredrickson, B. (2004). Resilient Individuals Use Positive Emotions to Bounce Back from Negative Emotional Experiences. Journal of Personality and Social Psychology, 86, 320-333. https://doi.org/10.1037/0022-3514.86.2.320

Umberson, D., Crosnoe, R., \& Reczek, C. (2010). Social Relationships and Health Behavior across the Life Course. Annual Review of Sociology, 36, 139-157.

https://doi.org/10.1146/annurev-soc-070308-120011

Ungar, M. (2004). The Importance of Parents and Other Caregivers to the Resilience of 
High-Risk Adolescents. Family Process, 43, 23-41.

https://doi.org/10.1111/j.1545-5300.2004.04301004.x

Van Tongeren, F., Hill, P., Krause, N., Ironson, G., \& Pargament, K. (2017). The Mediating Role of Meaning in the Association between Stress and Health. Annals of Behavioral Medicine, 51, 775-781. https://doi.org/10.1007/s12160-017-9899-8

Walsh, F. (1996). The Concept of Family Resilience: Crisis and Challenge. Family Processes, 35, 261-281. https://doi.org/10.1111/j.1545-5300.1996.00261.X

Walsh, F. (2003). Family Resilience: A Framework for Clinical Practice. Family Process, 42, 1-18. https://doi.org/10.1111/j.1545-5300.2003.00001.x

Walsh, F. (2012). Family Resilience: Strengths Forged through Adversity. In F. Walsh (Ed.), Normal Family Processes (pp. 399-427). New York: Guildford Press.

Walsh, F. (2015). Strengthening Family Resilience. New York: Guilford Publications.

Walsh, F. (2016a). Family Resilience: A Developmental Systems Framework. European Journal of Developmental Psychology, 13, 313-324. https://doi.org/10.1080/17405629.2016.1154035

Walsh, F. (2016b). A Family Developmental Framework: Challenges and Resilience across the Life-Cycle. In T. Sexton, \& J. Lebow (Eds.), Handbook of Family Therapy (pp. 30-47). New York: Routledge. https://doi.org/10.4324/9780203123584-3

Walsh, F. (2016c). Applying the Family Resilience Framework in Training, Practice, and Research: Mastering the Art of the Possible. Family Process, 55, 616-632. https://doi.org/10.1111/famp.12260

Waters, J. (2013). Snowball Sampling: A Cautionary Tale Involving a Study of Older Drug Users. International Journal of Social Research Methodology, 18, 367-380. https://doi.org/10.1080/13645579.2014.953316

Zambarloukou, S. (2015). Greece after the Crisis: Still a South European Welfare Model? European Societies, 17, 653-673. https://doi.org/10.1080/14616696.2015.1103887 